\title{
Critical Reflective Working Behaviour: A Survey Research
}

\author{
Marianne van Woerkom \\ University of Twente/ Stoas \\ Wim J. Nijhof \\ University of Twente \\ Loek F.M. Nieuwenhuis \\ Stoas
}

In this paper critical reflective working behaviour will be operationalized. Second, the question will be raised which factors have impact on critical reflective working behaviour. The following dimensions of critical reflective working emerge: reflection, vision sharing, challenging groupthink, asking for feedback, experimentation and awareness of employability. In a survey amongst 742 respondents these dimensions are validated. Important influencing factors seem to be selfefficacy and participation.

Keywords: Critical Reflective Behaviour at Work, Informal Workplace Learning, Learning Organisation

Good employees could be characterised as critical reflective employees. This conclusion is drawn from an explorative case study research in seven organisations: two banks, three factories (a cheese factory, a packaging factory, and a textile-printing factory), a call centre, and the Post Office (organisation). These case studies were a preliminary investigation for the main research, and were aimed at describing informal on-the-job learning and competence. In the preliminary study respondents representing different levels in the organisation gave answer to the question "What is your definition of a 'good employee?' Many respondents, especially in the packaging factory, the cheese factory and one of the banks, in answering this question stressed aspects baving to do with critical reflection (Van Woerkom et al., 2000). They mentioned the importance of thinking critically about the whys and wherefores, asking questions like "Why are things organised like this? Can the work be done more efficiently? Why do I work like this?" Main conclusion of the preliminary study is that critical reflection is both an important form of informal on-the-job learning and an important aspect of competence. The next step now is to make critical reflection operational and to look for factors that influence critical reflection. This paper discusses this next phase in the study. The research questions are: (1) What is critical reflection and how can we measure it? (2) What factors influence critical reflection?

\section{Theoretical Framework}

After having identified critical reflection as an important aspect of successful working behaviour, the concept of critical reflection needs to be defined. What exactly is critical reflection and how can we describe critical reflective individuals in work organisations? As Brooks (1999) rightly remarks, because the concept of critical reflection has been developed within the context of theory or practice, rather than research, (Freire, 1972, Mezirow, 1981, Brookfield, 1987 in Brooks, 1999) it has not been developed operationally and no instrument exists to identify individuals capable of critical reflection. Furthermore, scholars don't seem to agree on terminology and definitions. Some speak about critical reflection, while others speak of reflection, critical thinking, double loop learning, model II behaviour, transformative learning etc.

\section{Towards a Unifying Definition?}

As said before, many concepts are related to critical reflection, and many definitions exist of what critical reflection is. Let's try to find an operational definition that can help us to measure critical reflective working behaviour. According to Marsick and Watkins (1990) critical reflection relates to understanding one's own 
standards, goals, and interests, and learning about backgrounds, assumptions and performance objectives, aimed at improvement. The research of Marsick and Watkins (1990) showed that critical reflection enabled people to challenge norms and to examine the assumptions behind their reasoning and actions. According to Brooks (1999) the ability to ask (critical) questions is fundamental to 'informal critically reflective learning'. "Making inquiries stands as the only method we have to break us out of the worldviews we take for granted." According to Brooks, critical reflection is useful for improving work practices, addressing moral and ethical dilemmas, and evaluating organizational goals and strategies. A practical means of assessing the value of critical reflection is to measure whether it improves work practices. The concept of double-loop learning that Argyris and Schon (1996) distinguished is closely related to critical reflection. Double-loop learning enables workers to identify, question and change the assumptions underlying workplace organisation and patterns of interaction. Workers publicly challenge workplace assumptions and learn to change underlying values. Furthermore, Argyris \& Schon describe behaviour related to critical reflection and necessary for double loop leaming (so called model II behaviour). This can be characterised by asking (critical) questions, expressing one's (sincere) opinion and inviting others to give feedback or to confront visions, perspective taking and experimenting with new behaviour and work methods. Non-defensive behaviour is also part of model II behaviour. Brookfield (1987) defined the process of critical thinking as the process by which we detect and analyse the assumptions that underlie the actions, decisions and judgements in our lives. Essentially it has three stages: firstly, becoming aware that these assumptions exist, secondly, making them explicit, and thirdly, assessing their accuracy and validity. Bolhuis en Simons (1999) define critical learning as learning that is consciously initiated by the learner out of dissatisfaction with earlier learning. What has been learned before (frame of reference) has to be unlearned to make place for new knowledge, skills and attitudes. Critical learning can be seen as breaking down and building up.

This small sample proofs different characteristics of definitions and functions. Questioning assumptions seems to be a central aspect of most of the definitions but is not being made concrete in an organisational context. Assessing the usefulness for the purpose of this research, a few problems emerge: Most of these definitions are indeed not very operational, most of these definitions characterise a process instead of a visible behaviour and most of these definitions are rather focused on learning or thinking than on working in an organisation.

The model II behaviour (Argyris \& Schסn, 1996) seems to comply most with the purpose of our research. For this research it is important to make critical reflection operational in terms of observable examples of critically reflective behaviour in work organisations. Therefore the following definition of critical reflective working behaviour is being made: Critical reflective working behaviour is a set of connected, individual activities, aimed at analysing, optimising or innovating work practices on individual, team, or organisational level.

After finding the theoretical notions on critical reflection, again an analysis of the case-study material is being made, aimed at looking for identifiable, concrete, practical examples of these theories. The combination of literature review and the analysis of the case-studies (these were carried out in a parallel process, returning from one to the other) leads to the operationalisation of critical reflective working behaviour in nine dimensions, which are being chosen because they are recognisable both in theory and in practice. These dimensions will be discussed below, with examples of theory and the case-study material.

Reflection on Oneself in Relation to the Job. All fore mentioned authors bave an element of reflection in their definition. Reflection is a mental activity, aimed at examining one's own behaviour in a certain situation (Van Bolmuis-Poortvliet \& Snoek, 1996). The importance of reflection was demonstrated by statements from respondents like "reflecting on the whys and wherefores" "Why are things organised like this? Can the work be done more efficiently? Why do I work like this?" "Employees should be able to step back occasionally from their daily routine and devote more attention to self- and time management".

Learning from Mistakes. Reflection leads to consciousness of undesirable matters' (for example work routines, commmication deficiencies, mistakes, problems, lack of motivation). In stead of denying these undesired matters, they are interpreted as something positive, namely as source for improvement or learning. As Senge (1990) states "failure is, simply, a shortfall, evidence of the gap between vision and current reality. Failure is an opportunity for learning about inaccurate pictures of current reality, about strategies that didn't work as expected, about the clarity of the vision. Failures are not about our unworthiness or powerlessness". Many respondents from the casestudy's stressed the importance of 'not being afraid to make mistakes or showing one's vulnerability. When managers were asked for their definition of 'the learning organisation' they often mention the importance of learning from mistakes. 
Vision Sharing. Vision sharing is one of the observable activities caused by reflection. One expresses the result of reflection by expressing ones vision, asking (critical) questions or suggesting improvements. Making your vision publicly is one of the two central aspects of the model II behaviour (Argyris \& Schon, 1996). The respondents in the case-studies stressed the importance of contributing ideas and discussing this with others. "Good critical workers are not just being negative but do suggestions for a different way of working".

Challenging Group-think However critical thinking can not always be perceived as being positive. In Brooks case study of a "Baby Bell" telephone company, two images were used by many individuals to describe critically reflective participants. "The first was that they "can see the emperor is wearing no clothes", the second is that they "are troublemakers". Although being called a "troublemaker" does not appear to be regarded as bad, informal critical reflection is not always met with a welcoming embrace. It can be rejected, leaving an employee isolated." Brookfield defines critical thinkers as people who challenge group-think, that is, ideas that a group has accepted as sacrosanct. This also means that critical thinkers are alert to premature ultimates, invocations to higher values. Some respondents in the case-studies mentioned 'challenging group-think'. "The gury is a trouble-maker, but he sharpens us."

Asking for Feedback. The essence of model II behaviour of Argyris and Schön is the balance between advocating and inviting others for feedback and vision-sharing. Social dimension of critical reflective working behaviour. The importance of this dimension is demonstrated by statements of respondents referring to a social dimension of critical reflective working behaviour. On the one hand is social interaction an important source of information for reflection. On the other hand is "being critical on your own" often not perceived as constructive and effective. Employees operate in a social context and will have to get support for their ideas to imake things bappen.

Experimentation. Schon distinguishes between reflection-on-action en reflection-in-action. Reflection-inaction is a kind of experimenting. "When someone reflects in action he becomes a researcher in the practice context. He is not dependent on the categories of established theory and technique but constructs a new theory of the unique case." Experimenting is often mentioned as the last step in a reflection cycle (for example Dewey (1933), Korthagen (1985), Van Bolhuis-Poortvliet \& Snoek (1997). Brookfield (1987) perceives "exploring and imagening alternatives" as one of the two central activities of critical thinking. (The first is identifying en challenging assumptions). Although the term experimentation was not mentioned by respondents (it bas comotation of experimenting without any obligations) what they did mention was the importance of putting ideas into practice. "Good teams don't need a suggestion box; they immediately turn ideas into improvements".

Sharing Knowledge. Sharing knowledge can be seen as a dimension of non-defensive behaviour (Argyris \& Schon, 1996). Sharing knowledge means that people are not only motivated by protecting their own position but want to be part of something that is bigger than themselves (Senge, 1990). It also can be seen as a social aspect of critical reflection in the context of an organisation. As long as knowledge, insights, and visions are not being shared, the organisation won't benefit from it, and the individual will be frustrated in his attempts to change work practices. and Senge states that people don't only act out of self-interest, but although critical reflection seems to be an individual activity, the effect of it is not to be defined apart from the social context. The result of critical reflection (insights, visions, suggestions for improvements) can not be made effective if this is not shared with others. "Good workers like to share knowledge with their colleagues, without being afraid for competition" A training manager at a bank noticed that competitiveness amongst colleagues has a negative effect on knowledge sharing. More and more attention is paid to this problem.

Awareness of employability. Awareness of employability can be seen as a logical consequence of reflection. As a result of reflection about oneself in relation to work, people become aware of their motives and the extent to which work satisfies their motives. If necessary one will orient on other possibilities. This quality was stressed by many respondents. The case study material showed that both organisations and the people who work in them do benefit from employable employees who ask themselves if they really want to follow the changes in their job or if they would not prefer to look for another job. The ability to take responsibility for one's own career if one does not like the changes that are taking place in the job, and to continue this career with another employer is not only in the interests of the employee but also in those of the employer, if, for example, jobs change or disappear and employees cannot be dismissed because they are protected by law. 


\section{Factors Influencing Critical Reflective Working Behaviour}

The second research question is related to factors having impact on critical reflective working behaviour. In this paragraph an analysis is made of two clusters of factors: individual factors and factors related to work and organisation.

\section{Individual Factors}

Motivation. The theory of self-determination (Deci and Ryan, 1985, Deci and Flaste, 1995) expects three factors in workplace conditions to have a distinct impact on motivation for working and learning, namely experience of social integration, experience of autonomy and experience of competence. People feel socially integrated if they believe that their work is acknowledged by their colleagues and superiors and if they feel integrated in the community of work. People experience autonomy when they have the feeling that they bave the scope to act independently and to carry out their work according to their own planning and insights. People feel competent if they believe that they can carry out their work successfully and effectively. Another motivational component is the balance between insecurity and challenge in a situation (Maddi, 1970). An hypothesis in this research is that these four motivational components all have a positive effect on critical reflective working behaviour. However, the effect of social integration is still ambiguous. On the one hand feeling socially integrated will make it easier to be open, vulnerable and critical. On the other hand social integration can make it more difficult to resist social pressure and to come up with new ideas, ask (critical) questions etc.

Self-eficacy. Self-efficay is the belief in one's capabilities to organise and execute the sources of action required to manage prospective situations (Bandura, 1986). Self-efficacy also depends on self-evaluation and how people view their capability. For they may perceive an ability needed for some aspects of their current or anticipated future work either as an acquirable skill or as an inberent, possibly inherited aptitude. The former is highly conducive to skills development as people judge themselves in terms of performance improvement and regard errors a natural part of the learning process. The latter constrains learning, especially when people compare themselves unfavourably with others. Research from Van der Klink (1999) Gielen (1995), Gist, Stevens \& Bavetta (1991), Hastings, Sheckley \& Nichols (1995), Matieu, Martineau \& Tamenbaum (1993) show the significance of selfefficacy for motivation for training and commitment with organisation. An hypothesis in this research is that selfefficacy has a positive effect on the dimensions of critical reflective working behaviour because they require courage (daring to be vulnerable, to be open, to resist social pressure). People will have this courage if they have high efficacy. Eraut c.s. (1999) point out that confidence was frequently cited by respondents as both the major outcome of a sigmificant learning experience in the workplace and a critical determinant of good performance at work. Sometimes it derived from the achievement of a good result or the solution of a problem, sometimes from the recognition that others were no less fallible than themselves. Confidence encouraged more ambitious goal-setting and more risk-taking, both leading to further learning. Usually it was fairly specific, relating to ability to execute a task or successfully perform a role, what Bandura calls self-efficacy.

Experience Concentration. Experience concentration refers to the diversity of experience in ones career (Thijssen, 1996). In general, with the increasing of age, the multitude of experience increases and the diversity of experience decreases. The hypothesis is, that experience concentration has a negative effect on critical reflective working behaviour. The more experience one has in one context, the less one will put up for debate this particular context.

\section{Job and Organisational Characteristics}

Because critical reflective working behaviour is a type of informal on-the-job learning, we sought for theories about the effect that job characteristics have on on-the-job learning. Karasek's job demand control model is a model in which stress as well as learning are considered as dependent variables and task characteristics as independent variables (Karasek and Theorell, 1990). This model supposes a combination of high task demands and much control to lead to learning and to motivation for competence development. Task demands can be both quantitatively (workpace and workload) and qualitatively (for example alternation). High task demands are necessary for learning. To prevent stress, one needs control. Control (or decision latitude) is defined as the potential control of an employee over his tasks and his behaviour/performance during his working day. Control can refer to autonomy and participation. In a later version of this model, social support was added to this model (Kwakman, 
1999). Another theory is that of the learning potential of jobs (Onstenk, 1997) based on the work of Baitsch and Frei (1980). The learning potential refers to the likelihood of learning processes occurring in a particular job situation. This depends on a specific combination of worker characteristics and job characteristics. Leaming opportunities are determined by job characteristics (like breadth and variety of tasks, the degree of innovation and problem solving and the degree of control and autonomy), the information environment and the social environment (task group, co operation, guidance and feedback by supervisors and colleagues.

From these theories, the following job characteristics were selected because of their supposed impact on critical reflective working behaviour: workpace and workload, alternation, autonomy, task obscurity, information, participation in innovation and decision-making, co operation, communication (top down), coaching, and organisational learning climate. The hypothesis is that workpace and workload and task obscurity will have a negative effect, while the remaining variables will have a positive effect on critical reflective working behaviour.

Figure 1: Conceptual Model of Factors Influencing Critical Reflective Behaviour at Work

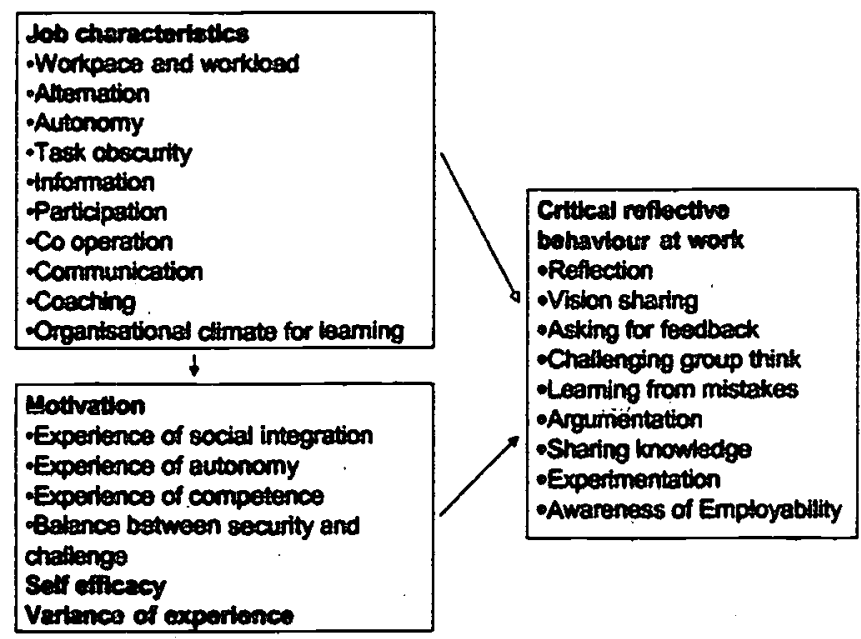

\section{Methodology}

Based upon the conceptual model a survey research is carried out in order to validate the nine variables of critical reflective working behaviour and the various predictor variables and to examine the relationships as specified in the conceptual model. The variables are being operationalised in a questionnaire for 'self-report' with on average six to eight items per variable. The items referring to workplace-conditions can be scored on a four-point scale $(1=$ hardly ever, 2 = sometimes, 3 =often, 4 = (almost) always). The items referring to critical reflective working behaviour can be scored on a six-point scale which only describes the extremes $(1=$ totally wrong....6 $=$ totally right).

It is evident that measuring a concept such as critical reflective working behaviour in a survey is a complex matter, and can only lead to a faint glimpse of the 'truth'. However, after a first phase of research that was qualitative, a need for a more quantitative foundation of concepts and relationships was felt Of course there are many problems involved with a questionnaire for self-report. Firstly, what a person says, is often not more than an indication of what he or she does. Secondly, persons are aware of the fact that the researcher is looking for something and thirdly, questions can evoke something that otherwise would have remained latently (van der Hoogstraten, c.s. 1985). The following attempts are taken to (partly) overcome these problems. Firstly, items are formulated as much as possible in terms of concrete behaviour in stead of feelings or thoughts. Secondly, a pilot of the questionnaire is tested on 20 people in various jobs. And thirdly, twelve respondents (scoring low, average and high on the instrument) are interviewed afterwards on the same indicators as in the questionnaire to check the consistency of their answers (results not available yet).

Participants are obtained from a data bank with school leavers of secondary and tertiary agriculture education and selected on the following criteria: Having a payed job, are working in an organisation of at least 20 employees and in a job which requires working together with colleagues.

Although the respondents have the same educational background, their work experience varies largely (production, financial services, education and consultancy, etc.). The questionnaires were sent in June 2000. 
Reminders were sent after two weeks. From the 1670 questionnaires that were sent, 742 valid questionnaires were retumed (respons rate of $46 \%$ ). $67,8 \%$ of these respondents are men, $32,2 \%$ are women. The average age is 29,8 years old $(S D=4,6)$. One-third of the respondents has a diploma of a secondary vocational ectucation, the rest has a diploma of tertiairy vocational education.

In order to answer the first research question (Is it possible to measure critically reflection?) factor and reliability analysis were carried out. In order to answer the second research question (What influences critical reflective working behaviour?) multiple regression analyses were carried out.

\section{Results and Findings}

\section{Reliability of the Instrument}

To determine whether the nine dimensions of critical reflective working behaviour really exist, a factor analysis (with principal components method and vari-max rotation) with nine factors to be extracted is carried out. This leads to the conclusion that the items belonging to reflection, reasoning and learning from mistakes spread among the other concepts. For the sub-scales reflection and learning from mistakes, this can be explained by their 'basic' character. These sub scales are in a way part of all the other sub-scales. For the sub scale argumentation this can be explained by the low reliability of the initial scale. Only after deleting three items, the scale reliability was acceptable $(\alpha=66)$. However, when in a next factor analysis items belonging to these three sub scales were removed, the rest of the six concepts come to the fore unambiguously in six factors with Eigen-values higher than 1 . After deletion of items loading less then .35 on any of the factors, these six factors explain $48,2 \%$ of the variance. Although this is not much, this solution leads to considerable data reduction. After carrying out reliability analysis deleting some items to improve the scale consistency, nine variables were being constructed by computing mean scores.

In order to find out if the sub-scales indeed load on one underlying construct, namely critical reflective working behaviour, again a factor-analysis (with principal components method and no rotation) is carried out on the nine variables without indicating a number of factors to be extracted. This leads to a two factor solution, with Eigenvalues higher than 1. It turns out that learning from mistakes, argumentation and sharing knowledge belong to another factor than the other sub scales. Because the most and the most important scales belong to the first factor, it is decided to eliminate the three sub scales that load on factor 2 . For the variables loading on the first factor a factor score is being computed which represents the concept of critical reflective working behaviour as a whole. This leads to the scales as described in Table 1. As we can see reliability of both the construct critical reflective working behaviour, and the underlying dimensions are fairly reasonable to high. Because of limited space, the reliabilities for the predictor variables are not being presented. The reliabilities of these variables varied between .70 and .91 .

Table 1. Descriptive Statistics For Sub Scales

\begin{tabular}{lrrrrr}
\hline & $M$ & Range & SD & Cronbach's alpha & Number of iterns \\
\hline Critical reflective working behaviour & -.003 & $-3.28-2.92$ & 1.00 & .76 & 6 \\
Reflecting & 4,35 & $2,00-6,00$ & .68 & .68 & 8 \\
Critical vision sharing & 4,11 & $1,29-6,00$ & .87 & .83 & 7 \\
Asking for feectback & 3,98 & $1,60-6,00$ & .77 & .83 & 10 \\
Challenging group-think & 4,40 & $1,20-6,00$ & .88 & .74 & 5 \\
Awareness of employability & 3,97 & $1,00-6,00$ & 1,25 & .80 & 4 \\
Experimenting & 3,83 & $1,17-6,00$ &, 84 & .75 & 6 \\
\hline \hline
\end{tabular}

\section{Effects on Critical Reflective Working Behaviour}

A stepwise regression was used to discern the relationship between (the sub scales of) critical reflective working behaviour and workplace and organisational characteristics and individual characteristics. The results are shown in Table 2 (only significant effects are shown). A large part of the variance on the factor score of critical reflective working behaviour is explained by the independent variables (51\%). The most important predictors are selfefficacy and participation. Also the explained percentage of variance in the sub scales critical vision sharing, challenging group-think and asking for feedback is fairly high (respectively $41 \%, 38 \%$ and $30 \%$ ). The most important predictors for critical vision sharing seem to be self-efficacy, participation and function level. The most important predictor for 'challenging group-think ' is self-efficacy. The most important predictors for asking for feedback seem to be self-efficacy and coaching. A relatively low percentage of the variance in the sub scales awareness of employability, experimentation and reflection is explained by the independent variables (respectively 
$14 \%, 17 \%$ and $19 \%$ ). Self efficacy and age seem to be the most important predictors for awareness of employability. Most important predictors for experimentation are self-efficacy and participation. For reflection the most important predictor is self-efficacy.

Table 2. Regression Analysis, the Effect of Workplace and Organisational Characteristics and Individual Characteristics on the Sub Scales of 'Critical Reflective Working Behaviour'.

\begin{tabular}{|c|c|c|c|c|c|c|c|}
\hline & $\begin{array}{l}\text { Critical } \\
\text { vision } \\
\text { sharing }\end{array}$ & $\begin{array}{l}\text { Asking for } \\
\text { Feedback }\end{array}$ & $\begin{array}{r}\text { Awareness } \\
\text { Of } \\
\text { employab. }\end{array}$ & $\begin{array}{l}\text { Challen- } \\
\text { ging group- } \\
\text { think }\end{array}$ & Experiment & Reflecting & $\begin{array}{l}\text { Factor score } \\
\text { CRWB }\end{array}$ \\
\hline \multicolumn{8}{|l|}{$\begin{array}{l}\text { Workplace and organisational } \\
\text { Feanures }\end{array}$} \\
\hline $\begin{array}{l}\text { Workpace and workload } \\
\text { Variety }\end{array}$ & .09 & & & & & .14 & . \\
\hline Participation & .35 & .12 & & .13 & 22 & & .20 \\
\hline Coaching & & .23 & & & & .08 & .09 \\
\hline $\begin{array}{l}\text { Organisational learning climate } \\
\text { Function level }\end{array}$ & $\begin{array}{r}-.08 \\
.17\end{array}$ & .13 & & & & .09 & \\
\hline Number of employees & & .12 & .08 & & & & .12 \\
\hline \multicolumn{8}{|l|}{ Individual feamures } \\
\hline Difficulty with change & & & & & -.11 & & \\
\hline $\begin{array}{l}\text { Self-efficacy } \\
\text { Function experience }\end{array}$ & .43 & .32 & $\begin{array}{r}.23 \\
-.11\end{array}$ & .55 & .26 & $\begin{array}{r}.28 \\
-.11\end{array}$ & .56 \\
\hline $\operatorname{Sex}(\operatorname{man}=1$ woman=0) & .11 & & -.14 & & & & .07 \\
\hline Experience concentration & & & -.11 & . & & -.10 & -.08 \\
\hline Age & & & -.21 & .10 & & & \\
\hline Explained variance ( $R$-square) & .41 & .30 & .14 & .38 & .17 & .19 & .51 \\
\hline
\end{tabular}

Again a stepwise regression is used to discem the impact of workplace and organisational characteristics on individual characteristics. Because of the importance of self-efficacy for critical reflective working behaviour, the most interesting thing is to discern which factors have impact on self-efficacy. It turns out that only a small percentage of the variance in self-efficacy can be explained by the predictor variables (14\%). The most important predictor for self-efficacy seems to be participation.

\section{Conclusions and Recommendations}

Critical reflective working behaviour seems to be a construct consisting of six dimensions, namely reflection on oneself in relation to the job, critical vision sharing, challenging group-think, asking for feedback, experimentation and awareness of employability. Both the sub-dimensions and the construct as a whole seem to be reliable concepts. With regards to the effects of the predictor variables the most striking result seems to be the effect of self-efficacy on all the different sub-scales of critical reflective working behaviour. This can be explained by the fact that all the sub scales of critical reflective working behaviour imply a certain way of risk taking behaviour. One has to bave courage to withstand social pressure and be critical, to take a vulnerable position and ask for feedback, to take a close look at ones performance and ones future career, to experiment in stead of walk the beaten track. People who feel confident will sooner be prepared to take such 'risks'. Second important result seems that that workplace and organisation characteristics (except for participation in policy and decision making) are not very significant for critical reflective working behaviour. Workplace characteristics that were being selected based upon the theories about the learning potential of jobs from Karasek (1990), Onstenk (1997) and Baitsch and Frei (1980) probably refer more to forms of single-loop learning than to forms of double loop learning. This means that if critical reflective working behaviour indeed is an indicator for double loop learning, it is quite hard for organisations to stimulate it. If organisations do want to stimulate double-loop leaming this has to be achieved via stimulating employees selfefficacy. The problem with self-efficacy however is that this is both an outcome of a significant learning experience in the workplace and a critical determinant of good performance at work (Eraut, 1999). A way to break this vicious circle could be to gradually build up the uncertainty employees have to deal with in their job. In other words, people should start to operate in a safe environment where they can develop their competence, and develop their own vision on the job. After this they should be challenged to push back frontiers and be invited to think about policy and decision making and innovation in the organisation. The fact that the scale 'self-efficacy' is so much more significant than 'experience of competence' seems to indicate that self-confidence indeed is fairly specific and related to the ability to perform a specific task. In a way one could also argue that an experience of incompetence (conscious incompetence) though combined with self-confidence is the best catalyst for learning. As Lee (2000) 
states in her discussion of the 'learning ladder' "It is very easy to become so immured to the struggle and the need for achievement that one becomes unconsciously competent at 'doing the job'. So much that one no longer takes time to be 'conscious' or aware of why the job is being done in the first place". This can be illustrated by an interview with a software engineer who scored high on the dimensions of critical reflective working behaviour and who stated in a confident way that he was insecure. "Being insecure for me is part of the job, you make many choices under time pressure when you are still not sure about the best solution. I know some colleagues who are never insecure and who sometimes fervently advocate a solution while I can think of ten reasons why to choose for another option."

\section{How This Research Contributes to New Knowledge in HRD}

As the transfer of training is a very complex matter, HRD should focus more on how to make use of the informal learning experiences that derive from everyday working life, instead of on formal training. True organisational (double loop) learning can only happen when management and employees work in a critical reflective way. As Franz (1999) states, you can people force to work, but you can not force people to work well. In order to work well, people must be able to (collectively) put up for discussion their day to day work practices. It seems that critical reflection brings together the interests of both employers and employees. The benefits of critical reflection to the employee lie in the critical reflection itself, which gives him a feeling of self-determination, growing personal mastery and which will help him in career development. For the employer, however, it is the economic value of critical reflection that is of importance. Critical reflection is essential for continuous improvement, quality management and innovation - all matters that are vital in order to survive in a competitive economy.

\section{References}

Argyris, C., \& Schơn, D..A. (1996). Organizational learning II: Theory method and practice. Reading, MA: Addison-Wesley Publishing Company.

Bolhuis, S.M., \& P.R.J. Simons (1999). Leren en werken. Kluwer, Deventer.

Brookfield, S.D. (1987). Developing critical thinkers. Jossey-Bass Publishers, San Francisco.

Brooks, A.K. (1999). Critical reflection as a response to organizational disruption. In V. J. Marsick \& M. Volpe (Eds.), Informal learning on the job (pp. 67-97). San Francisco: Berret-Koehler.

Deci, E.L. (1975). Intrinsic motivation. New York, NY: Wiley.

Deci, E.L., \& R.M. Ryan (1985). Intrinsic motivation and self-determination in human behavior. New York, NY: Plenum Pressrk.

Deci, E.L., \& Flaste (1995). Why we do what we do. The dynamics of personal autonomy, New York, NY: GrossetPutnam.

Dewey, J. (1933) How we think: A restatement of the relation of reflective thinking to the echucative process. Boston, MN: Heath \& Co.

Kleinmam, M., \& Straka, G.A. (1996). Selbstlernbereitschaft und erlebte Arbeitsplatzbedingungen von Beschafitgten in kaufimannisch-verwaltenden Berufen. Ergebnisse einer empirischen Pilotstudie. In: P. Sloane: Tagungsband zur Herbsttagung der Kommission Berufs- und Wirtschaftspadagogik der DGfE in Kassel.

Korthagen (1985). Reflective teaching and pre-service teacher education in the Netherlands. Journal of Teacher Education, 36(5), 11-15.

Marsick, V. (1987). Leaming in the workplace: Theory and practice. London: Croom Helm. Routledge.

Marsick, V.J., \& Watkins, K.E. (1990). Informal and incidental learning in the workplace. London:

Doubleday.

Senge, P.M. (1990). The fifth discipline: The art and practice of the learning organization. London,

Schon, D.A. (1987). Educating the reflective practitioner. San Francisco, CA: Jossey-Bass.

Press.

Sternberg, RJ. (1985). Beyond 1Q: A triachic hieranchy of human intelligence. New York, NY: University

Stemberg (1988). The triachic mind A new theory of human intelligence. New York, NY: Viking.

Thijssen J.G.L. (1996). Leren, leeftijd en loopbaanperspectief [Earning, age and career prospect] dissertation Katholieke Universiteit Brabant.

Van Bolhuis-Poortvliet, \& Snoek (1996) Reflecteren op stage-ervaringen Rijksuniversiteit Groningen (dissertation). 